\title{
TRAZAS DEL MITO Y LA TRADICIÓN CLÁSICA \\ EN LA CANTIGA PROFANA \\ GALLEGO-PORTUGUESA
}

\author{
Rafael J. Gallé Cejudo* \\ Universidad de Cádiz
}

\section{RESUMEN}

En este artículo se presentan algunas de las concurrencias que podemos encontrar entre la tradición literaria clásica y las cantigas gallego-portuguesas, que, en ocasiones, dotan de un nuevo significado a la tradición mítica grecolatina. En este sentido, ciertos mitos clásicos son reelaborados desde un punto de vista moral. Asimismo, se muestra, a modo de ejemplo, el recurso a tópicos eróticos propios de la tradición grecolatina en la cantiga de amor gallegoportuguesa, tales como el amor a primera vista, la locura de amor, la pérdida del juicio, la amante esquiva, la irrisor amoris y el servitium amoris.

PAlabras Clave: mitología, tradición clásica, cantigas gallego-portuguesas, literatura erótica grecolatina.

\section{TRACES OF MYTH AND CLASSIC TRADITION IN \\ THE GALLEGO-PORTUGUESE PROFANE SONG}

\section{Abstract}

This article goes through some of the coincidences between the classical literary tradition and the Galician-Portuguese lyric, which provide sometimes a new signification to the Greco-Roman mythical tradition. In this sense, certain classical myths are reworked from a moral perspective. Additionally, the resource to erotic topics from the Greco-Roman tradition in the Galician-Portuguese love lyric is exemplified, such as the love at first sight, the madness of love, the judgment loss, the evasive lover, irrisor amoris and servitium amoris. KEYwORDs: myths, classical tradition, galician-portuguese lyric, greco-roman erotic literature. 
La cantiga 5 del corpus de Alfonso X el Sabio ofrece un aparentemente sencillo y al mismo tiempo desalentador empleo del mito clásico en función paradigmática o ejemplificativa:

Alfonso X el Sabio (B 468 ${ }^{\text {bis }}$, LPGP 18.5) ${ }^{1}$

Ben sabia eu, mia senhor, que, pois m' eu de vós partisse, que nunc' aveeria sabor de ren, pois vos eu non visse; porque vós sodes a melhor dona de que nunca oisse homen falar, ca o vosso bóo semelhar sei que par nunca lh' omen pod' achar.

$\mathrm{E}$, pois que o Deus assi quis, que eu sốo tan alongado de vós, mui ben seede fis que nunca eu sen cuidado en viverei, ca ja Paris

d'amor non foi tan coitado nen Tristan; nunca sofreron tal afan, e nen an, quantos son nen seeran. [...]

Se trata de una cantiga de amor con el trasfondo del tema de la despedida y la coyta del poeta, porque ya no va a poder ver a su amada. En los versos 5-6 de la segunda cobla el poeta se sirve de la figura mítica de Paris, príncipe de Troya, hijo de Príamo y Hécuba, en función paradigmática, no como estructura alusiva (suasoria o disuasoria), sino como estructura emblemática; es decir: el mito como apoyo doctrinal que se cita para comprobar, ilustrar o autorizar un aserto, doctrina u opinión (me voy a atener a lo largo de estas páginas a la nomenclatura metodo-

* Agradecimiento expreso al MINECO por su apoyo al Proyecto FFI2017-85015-P «Las migraciones temáticas entre la prosa y el verso: el papel referencial de la elegía helenística». Agradezco al IEMYR su amable invitación para participar en este volumen, pero debo dejar pública constancia de que mi acercamiento a la lectura de los cancioneros gallego-portugueses se ha hecho desde la humildad del lector no experto; más bien desde la perspectiva de un filológo clásico que bajo ningún concepto se atrevería a invadir las competencias científicas de mis colegas romanistas.

1 Salvo que se especifique otra cosa, citaremos el texto de las cantigas siempre por M. BREA, e.a. (comp.), Lírica profana galego-portuguesa I-II, Santiago, Xunta de Galicia, 1996 (en adelante BREA, $L P G P)$. 
lógica establecida por Rosa Romojaro²). Las penas de amor de Alejandro o Tristán serán el modelo con el que el poeta sobrepuja (si queremos acogernos a la terminología de Curtius ${ }^{3}$ ) su propio pesar. Ahora bien, este podría ser un ejemplo aparentemente sencillo, pero al mismo tiempo desalentador. A su supuesta sencillez me referiré más adelante, pero su carácter descorazonador le viene dado (y con esto les anuncio ya la gran aporía a la que se enfrenta este trabajo) porque es el único ejemplo de referencia mítica clásica grecolatina que he encontrado en todo el corpus de cantigas profanas gallego-portuguesas (en las más de 1640). Y se puede asegurar que este hecho es francamente sorprendente. No son pocos los estudios y congresos periódicos que se celebran en España y más allá de nuestras fronteras en los que prácticamente se han peinado todas las épocas de la literatura española e hispanoamericana en busca de reminiscencias mitológicas grecolatinas y ecos de tradición clásica. Pues bien, sabido es que raro es el género o autor hispano (sea de la época que sea) en cuya obra no se pueda rastrear esa presencia, esa reescritura, de alguno de los mitos clásicos grecolatinos.

Sin embargo, no es este el único hecho sorprendente en el caso de las cantigas. Por una parte, se podría pensar que esta "sequía» mitológica grecolatina en la cantiga profana pudiera deberse a una presencia mayoritaria de la mitología bíblica (o cristiana) que, en detrimento de la pagana clásica, hubiera copado los principales usos y funciones que el mito clásico suele cumplir en la literatura hispana y occidental. Pero no es así, ya que, si se exceptúan las menciones de Dios, María y varios santos (sobre todo en las cantigas de romería), apenas es rastreable en el corpus de cantigas profanas alguna mención de Adán y Eva (LPGP 5.1, 18.9), Sodoma y Gomorra (LPGP 56.5), Judas y el Paraíso (LPGP 118.2, 125.30) o Sansón (LPGP 145.9 apéndice I). Y, por otra parte, es igualmente sorprendente, porque cuesta imaginar que un tipo de literatura que ha sabido aquilatar tan bien los principales temas, motivos y tópicos literarios de la literatura amatoria clásica haya buscado al mismo tiempo soltar el lastre de todo el andamiaje mitológico que en mayor o menor medida sustenta la lírica clásica grecolatina ${ }^{4}$.

Hecho este adelanto de los resultados del rastreo sobre el corpus de cantigas profanas y planteados algunos de los principales escollos a los que se enfrenta el estudioso, es necesario establecer los antecedentes que han marcado las pautas de este estudio 5 . Debo reconocer, en efecto, que mi principal interés por esta obra

2 R. Romojaro Montero, Funciones del mito clásico en el Siglo de Oro, Granada, 1998, p. 120 y ss. (en adelante Romojaro, Funciones)

${ }^{3}$ Cfr. E.R. Curtius, Literatura europea y Edad Media latina, México, Fondo de Cultura Económica, 1955, pp. 235-239, y las acertadas matizaciones de J.M. ${ }^{a}$ Maestre Maestre, «El tópico del sobrepujamiento en la literatura latina renacentista». Anales de la Universidad de Cádiz, vol. v-vi (1988-1989), pp. 167-192.

${ }_{4}^{4}$ Sería interesante, sin duda, comprobar en qué medida lo pudieron hacer previamente los travadores provenzales, que son los iniciadores de esta tradición lírica, pero eso sería objeto de otro trabajo de investigación.

${ }^{5}$ Las siguientes reflexiones vienen a complementar y nutrir de ejemplos las ya expresadas en R.J. Gallé CEJUdo, «Reminiscencias literarias clásicas en la lírica profana medieval gallego- 
se produjo en un primer momento por la naturaleza misma de la lengua en la que estaba escrita. Creo que las palabras de D. Ínigo López de Mendoza, marqués de Santillana, en el Prohemio e carta al Condestable D. Pedro de Portugal, resumen exactamente el origen de mi admiración: «Non ha mucho tiempo qualesquier deçidores o trovadores destas partes, agora fuessen castellanos, andaluces o de la Extremadura, todas sus obras componían en lengua gallega o portuguesa» ${ }^{6}$.

Pues bien, a partir de ese momento (y al margen del tópico que a lo largo de la tradición crítico-literaria venía a sostener que los cancioneiros escapan de los límites exactos de lo que podría ser considerado literatura española o literatura portuguesa sensu stricto) reconozco que como helenista me sentí admirado y animado a profundizar en su estudio, no solo por la legitimidad literaria que los escritores del ámbito hispano concedían a esta coiné literaria gallego-portuguesa, sino también por el convencimiento de que, a nivel diafásico, se trataba de una especie de lingua franca (común a gallegos, portugueses, leoneses, castellanos y aragoneses) equiparable en gran medida a cualquiera de las modalidades que en este sentido surgieron en el territorio heleno a lo largo de la historia de la lengua griega: p. e., el jonio asiático para el drama o la filosofía presocrática, el dorio para la poesía coral, el lesbio de la monodia o, por encima de todos, el epos homérico, que fue transversal a toda la poesía épica (y lírica también) desde Hesíodo (s. viı a.C) hasta Nono de Panópolis (s. v d.C.).

Pero, aparte de los rasgos puramente lingüísticos y, si me apuran, métricos, lo cierto es que la cantiga profana gallego-portuguesa presenta una semejanza tan estrecha desde el punto de vista formal y, por supuesto, en los contenidos con la lírica y la epigramática clásica grecolatina que, sin ánimo de parecer dogmático en este punto, sí quisiera dedicar unos minutos para revisar, aunque sea muy de pasada, la cuestión de los orígenes e insistir sobre un dato al que quizá no se le ha dado suficiente importancia.

Se ha sostenido como premisa genérica básica ${ }^{7}$ que la canción gallego-portuguesa hay que entenderla como la fusión de dos corrientes líricas: de una parte, una canción cortesana, con influjo provenzal; y, de otra, una poesía autóctona, casi seguro no popular, sino mezcla de una tradición medieval latina y litúrgica con elementos tomados del folclore. En el caso del lirismo cortesano con influjo provenzal, se trataría de esas formas afrancesadas y provenzales que por el prestigio que habían adquirido los conceptos y expresiones irradiados desde el sur de Francia se aclimataron en la península en el período prealfonsí. Posteriormente, la toma de Sevilla

portuguesa», en P. MorÂo y C. Pimentel (eds.), Matrizes clássicas da literatura portuguesa: uma (re)visâo da literatura portuguesa das origens à contemporaneidade, Lisboa, Campo de Comunicaçâ, 2014, pp. 23-34.

${ }^{6}$ Cito por A. Tarrío Varela, Literatura gallega. Madrid, Taurus, 1988, p. 11. Véase también Á. Gómez Moreno, El Prohemio e Carta del Marqués de Santillana y la teoría literaria del s. XV, Barcelona, Ed. Univ. de Barcelona, 1990.

7 X.R. Pena, Literatura galega medieval, I-II, Barcelona, Sotelo Blanco, 1986, p. 57 (en adelante Pena, Literatura galega). 
(1243) y la incorporación del Reino de Murcia (1261) fueron el acicate para la permanencia de caballeros portugueses y también para la llegada de numerosos poetas provenzales ${ }^{8}$. En el caso de esa poesía autóctona, ya hibridada con elementos cultos y folclóricos, los argumentos para explicar la génesis del lirismo trovadoresco en la Europa occidental han partido de ordinario de un triple origen representado por las tesis folcloristas, las medio-latinas y las arábigo-andaluzas. Y aunque hoy la crítica prefiera barajar argumentos de compromiso entre las tres, no han faltado voces que han recurrido al pasado clásico dentro de cada una de estas corrientes. Así, entre los defensores de la tesis folclorista, caben ser destacados los argumentos que retoman las tesis románticas enunciándolas como vestigios de una tradición popular señalada por las maias o los mayos, que no serían sino una proyección en la Edad Media de un antiquísimo culto a Venus durante la celebración de la primavera. Por otra parte, la tesis medio-latina (que englobaría la litúrgica y la paralitúrgica) parte de la premisa de que los trovadores eran gente de cultura y de que la literatura medieval latina fue patrimonio de minorías ilustradas de la época en toda la Europa occidental. Y, por último, en lo que atañe a la tesis arábigo-andaluza, la crítica se debate entre si fue imposición por la dominación árabe o bien un trasvase de culturas. Y digna de mención en este apartado sería la hipótesis de Burdach, quien sostiene que los puntos comunes entre el mundo hispano-árabe y el lirismo trovadoresco no significan imitaciones directas de los modelos arábicos, sino que son reflejo de una misma antigua y vasta tradición literaria que ya estaba en la cultura grecolatina, en especial en la escuela poética del helenismo alejandrino. El autor llega a la conclusión de que la lírica de los trovadores es un producto de la orientalización de la cultura grecolatina, orientalización consistente en la apropiación de temas y tendencias del lirismo árabe?

Pues bien, en este punto me gustaría recordar un argumento más (una hipótesis que ya enunciara E. Gangutia y de la que se han hecho eco algunos importantes helenistas ${ }^{10}$ ) que abre una nueva vía de acceso hasta ahora no suficientemente explorada y que de alguna forma podría ser transversal (por su antigüedad) a las dos principales corrientes líricas y a las tesis folcloristas, las medio-latinas y las arábigo-andaluzas.

${ }^{8}$ C. Alvar y V. Beltrán, Antología de la poesía gallego-portuguesa, Madrid, Alhambra, 1985, pp. 5-6 (en adelante Alvar y Beltrán, Antología).

9 Véase PenA, Literatura galega, p. 51 y ss., aunque podría tratarse más bien de poses y formas literarias más que de contenidos.

${ }^{10}$ Cfr. E. Gangutia Elícegui, «Poesía griega 'de amigo' y poesía arábigo española». Emerita, vol. 40 (1972), pp. 329-396; "Algunas notas sobre la literatura griega y Edad Media española». Estudios Clásicos vol. 16 (1972) 171-181; y Cantos de mujeres en Grecia, Madrid, Ediciones Clásicas, 1994 (en adelante Gangutia, Cantos de mujeres); J.A. Fernández Delgado, «Antecedentes griegos de la primera literatura gallega», en M.C. Díaz y Díaz (ed.), Primera reunión gallega de estudios clásicos, Santiago, Universidad, 1981, pp. 407-417; y F. Pordomingo Pardo, La poesía popular griega. Estudio filológico y literario, Salamanca, Universidad, 1979, todos con abundante bibliografía adicional. Me tomo la libertad de recomendar igualmente la obra de P. Lorenzo Gradín, La canción de mujer en la lírica medieval, Santiago de Compostela, Universidad, 1990. 
Sabido es que uno de los contenidos principales en la cantiga es el escarnio y la temática obscena, a veces de una obscenidad sutil, velada, anfibológica, con primacía del doble sentido o la alusión, pero a veces también de una obscenidad descarnada (un saco de carajos para una abadesa 38.3, monje descarajado 38.2, el que compara su pene con su caballo 70.50 , etc.). Son cantigas de carácter más escatológico y obsceno y en ellas se pretende ridiculizar o denunciar mediante la sátira política, social, religiosa o personal, atacando los defectos físicos, los vicios -en su mayoría sexuales- o la infidelidad conyugal, etc. Pues bien, esta temática, e incluso con el mismo tratamiento formal (dobles sentidos, retruécanos, anfibologías, etc.), está ya en la poesía epigramática griega, en la elegía, la comedia, el mimo, etc.; hay, sin embargo, un subgénero lírico griego específico que tiene un correlato perfecto en la cantiga. Me refiero al género lírico popular de la llamada canción locria (el ancestro poético del relato milesio que de tan gran fortuna gozó en la literatura grecolatina antigua). Son poemas cuya protagonista femenina encarna el topos de la malmaridada, de la malcasada, de la adúltera y que por lo general pide al amante que abandone la cama antes de que llegue el marido. No faltará, en efecto, la referencia al marido ausente, al que nunca se nombra directamente: en griego será «aquel», y en la cantiga el «irado», «mal bravo», «sanhudo» o «esquivo» ${ }^{11}$ :

En el siguiente ejemplo de D. Denis, rey de Portugal, la joven confiesa que teme los celos del marido y maldice su matrimonio. Maldice incluso a Dios por haberle proporcionado el marido:

$$
\begin{aligned}
& \text { Don Denis (B 585, V 188, LPGP 25.102) } \\
& \text { Quisiera vosco falar de grado, } \\
& \text { ay meu amigu'e meu namorado! } \\
& \text { mays non ous' oj' eu convosc'a falar } \\
& \text { ca ey mui gram medo do hirado. } \\
& \text { Hirad'aja Deus quem me lhi foy dar! }
\end{aligned}
$$

[se repetirá en el cuarto y quinto verso de todas las coblas:]

ca ey mui gram medo do mal bravo

Mal brav'aja Deus quem me lhi foy dar! [...]

ca ey mui gram medo do sanhudo

Sanhud'aja Deus quem me lhi foy dar! [...]

ca ey mui gram medo do esquivo.

Esquiv'aja Deus quem me lhi foy dar!

En la literatura griega tenemos varios ejemplos emblemáticos de este tipo de canción, pero sin duda el pasaje más interesante desde el punto de vista metaliterario es el siguiente tomado de la obra de Ateneo:

\subsection{4).}

${ }^{11}$ Véase también «Martin de Cornes vi queixar», de Pero da Ponte (B 1647, V 1184, LPGP 
Ateneo, Banquete de los eruditos $15.697 \mathrm{~B}$

Dijo esto Demócrito y Cinulco añadió: «... Este (sc. Ulpiano) prefiere las canciones picantonas a las serias. Por ejemplo, las llamadas canciones locrias, de las que algunas tienen cierta naturaleza adúltera, como por ejemplo esta:

Oh, ¿qué es lo que te pasa? No nos delatemos ambos, te lo ruego.

Antes de que aquel llegue, levántate,

no te vaya a causar una terrible desgracia a ti, y también a mí, desdichada.

Ya es de día, ¿no ves la luz por la ventana?

En verdad, de este tipo de canciones toda Fenicia, su patria, está llena. E incluso él mismo la recorría tocando la flauta con los que componen las llamadas «canciones puercas» (kolábrous), pues ese es su nombre, querido Ulpiano» ${ }^{12}$.

Habría que fijar la atención sobre la frase En verdad, de este tipo de canciones toda Fenicia está llena. Creo que los contactos fenicios con el sur de Francia y de España están fuera de toda discusión. Y si en la costa de Asia Menor, en la ciudad de Marissa se ha descubierto uno de los ejemplos papiráceos más emblemáticos de un canto de mujer (el llamado canto Marissaeum ${ }^{13}$ ), ¿podemos descartar con seguridad esta vía de acceso también en la península Ibérica o en la Provenza? Difícilmente se puede negar esta hipótesis con rotundidad.

Volviendo al tema que nos ocupa, como ya se ha indicado, los grandes referentes (personajes, episodios, sagas, etc.) mitológicos clásicos grecolatinos están ausentes de corpus de cantigas profanas. Al inicio de este artículo se citaba el ejemplo de Paris en la cantiga 5 de Alfonso X y aludía a la aparente sencillez del referente mítico. Como bien indica Alvar ${ }^{14}$, el mismo rey Alfonso, inspirándose en el texto de Dares el Frigio, incluye ya la Guerra de Troya en su General Estoria (parte I, edad II) y, además, el Libro de Alexandre, uno de los manuales básicos de los nobles que aspiraban a entrar en el selecto círculo de letrados en las cortes de Fernando III y Alfonso X, dedicaba ya una importante extensión a ese episodio belico (estrs. 320 a 470). Además, el empleo de las figuras míticas de Tristán y Paris como paradigmas amorosos podría ser prueba del empeño del rey Sabio por dotar a la corte de la clerecía, es decir, de una formación intelectual preeminente. Por otra parte (añade Alvar), los amores de Paris y Helena se habían convertido en referente literario en Occidente desde principios del siglo XII, especialmente tras la difusión del Roman de Troie, de Benoît de Sainte-Maure. Y los trovadores catalanes Guerau de Cabrera (m. a. 1170) y Guiraut de Calanson recomiendan la materia troyana entre los conocimientos que deben tener sus juglares, y otros, como Guilhem Ademar (xi 65-66) o Arnaut Daniel (III 45-48), ya mencionan los amores de Paris y Helena en sus

${ }^{12}$ Las traducciones de los textos griegos son siempre personales.

13 Se trata de un diálogo amoroso en verso de época helenística en el que una mujer se ufana de su libre albedrío en las relaciones amorosas. Puede leerse en versión bilingüe en GANGUTia, Cantos de mujeres n. ${ }^{\circ}$ 49a. Muy ilustrativo puede resultar también el artículo de la misma autora E. GANgutia Elícegui, «Los “cantos de mujeres”. Nuevas perspectivas». Emerita vol. 78.1 (2010), pp. 1-31.

${ }^{14} C f r$. C. Alvar, «Don Denís, Tristán y otras cuestiones entre materia de Francia y materia de Bretaña». e-Spania, vol. 16 (2013) sin paginación. 
obras. Todo este brillante razonamiento del profesor Alvar parte de la idea de que nadie podría poner en duda los amores de Paris por la hija de Zeus y Leda, como sentimiento paradigmático por cuya pasión llegó incluso a desatarse la mismísima Guerra de Troya. Pero precisamente ahí reside una de las claves de la complejidad de este paradigma mítico; ahí es donde se produce la reescritura del referente mítico clásico: la relación erótica de Paris y Helena es una relación adúltera y por lo tanto es un ejemplo que no se debe seguir. La relación adúltera de Paris y Helena se emplea generalmente en la literatura griega en función paradigmática, sí, pero como estructura alusiva disuasoria; es decir: caso o hecho sucedido en un tiempo fabuloso que se propone, no para que se imite y se siga porque es bueno y honesto, sino para huir de él y evitarlo porque es indigno o inmoral ${ }^{15}$. Y este empleo disuasorio de los amores míticos de Paris y Helena no es medieval, porque lo tenemos ya en la obra de Homero, en la propia Ilíada, la obra más antigua conservada de la literatura griega y de la literatura occidental. Son muchos los pasajes que recogen esta idea, pero el más explícito es sin duda el del episodio de la teichoscopía: Príamo y los ancianos troyanos se han asomado a la muralla que domina la puerta Escea (izquierda) de Troya para contemplar las tropas griegas. Y el rey pide a Helena que se acerque y que identifique para él algunos de los caudillos griegos:

Homero, Iliada III, 161-180:

Así decían ellos, y Príamo en voz alta llamó a Helena: «Ven aquí, amada hija, y toma asiento delante de mí, para que veas a tu primer marido y a sus parientes y a los tuyos. No eres tú para mí en nada culpable, pues para mí culpables son los dioses, que han desatado esta guerra de aqueos lacrimosa contra mí. Dime cómo se llama ese varón enorme, ese aqueo, quién es este guerrero noble y alto. Es verdad que hay otros aun más altos que le sacan incluso una cabeza, pero hombre tan hermoso yo hasta ahora jamás he visto con mis ojos, ni tan majestuoso, pues se parece a un rey». Y a él Helena, divina entre mujeres, le respondía con estas palabras: «Me inspiras un temor reverencial, suegro mío. ¡Ojalá que una muerte cruel me hubiera sido grata el día que hasta aquí vine siguiendo a tu hijo, tras abandonar mi tálamo nupcial, mi familia, a mi tierna hija y a las de mi edad! Pero no fue eso exactamente lo que ocurrió, y por eso ahora me consumo llorando. Responderé a aquello por lo que me preguntas y me inquieres: precisamente ese es el Atrida Agamenón de dilatado imperio, rey noble y al mismo tiempo esforzado lancero. En otro tiempo era mi cuñado ¡mío, que soy una cara de perra!, si es que eso pasó alguna vez».

Lo más importante del pasaje, sin duda, son las palabras de Príamo en cuanto a la exención de culpabilidad de Helena y la ética homérica: en cualquier determinación que toma el hombre está siempre presente el dios; falta el concepto de decisión en el héroe homérico al no existir el alma o persona; sin embargo, no es totalmente irresponsable, porque la última decisión siempre la tiene que tomar él mismo, y eso es lo que precisamente reconoce Helena (nótese que el llamarse a sí

${ }^{15}$ Cfr. Romojaro, Funciones, p. 111 y ss. 
misma 'cara de perra' no es cuestión baladí, dada la indignidad de este animal en el mundo antiguo). Pero en el contexto del presente estudio el pasaje es idóneo para ejemplificar la reescritura del referente mítico clásico en la cantiga alfonsí. El rey Sabio podría haber optado por otros amores emblemáticos que a priori no plantean ningún tipo de ambigüedad o de duda sobre su valor modélico (como los de Héctor y Andrómaca, Odiseo y Penélope, Aquiles y Briseida, por citar solo algunos de los más conocidos en la epopeya homérica); sin embargo, reescribe el mito haciendo de los amores adulterinos de Paris y Helena un modelo con el que compararse, quizá, como se ha seńalado, por el dolor que provocan en el amante.

Dentro de la función tópico-erudita con la que los autores hispanos instrumentan el uso del mito clásico, una de las fórmulas o procedimientos con los que estas funciones se desarrollan sería la mitologización: el paso de la abstracción a la concreción mítica o la «adquisición de la singularidad que convierte a nombres comunes y abstractos en nombres propios que personifican los actantes del mito» ${ }^{16}$ (Fortuna, Psique...). En el caso de la cantiga profana hay un ejemplo de mitologización que se repite sistemáticamente (he contabilizado casi medio centenar de casos). Se trata de la personificación de $\mathrm{Amor}^{17}$. Ahora bien, entender que en alguno de estos ejemplos hay una reescritura, una reutilización del Eros (del Cupido) mitológico clásico es ciertamente improbable. Es verdad que en casi todos los ejemplos de este Amor implacable, quejas a Amor, este Amor injusto, cruel, hiriente, en casi todos los casos podríamos encontrar un paralelo clásico, pero cuesta creer que sea más allá de un lugar común de la literatura erótica universal.

Como ya he indicado, los grandes referentes mitológicos clásicos grecolatinos están ausentes del corpus de cantigas profanas. Sin embargo, si descendemos a estructuras menores dentro del propio mito, sí se pueden encontrar algunos puntos de contacto significativos. En la cantiga medieval se produce una suerte de atomización del referente mítico por la cual, si bien no se va a encontrar la poetización de relatos míticos íntegros en los que el autor se atiene a los modelos clásicos de narración, sí se va a producir, no obstante, un tipo de innovación mítico-literaria; es decir, "creaciones poéticas en las que a partir de elementos y personajes del mito clásico, el poeta compone un nuevo relato, trama mítico-poética innovadora, no registrable en la herencia narrativa clásica» ${ }^{18}$.

Un ejemplo concreto de esta individualización de mitemas concretos se puede leer en la cantiga 4 del corpus de Pero Gómez Barroso y su adaptación parcial del mito de las Edades hesiódico:

${ }^{16}$ Definición tomada de Romojaro, Funciones, p. 52 y ss.

17 Sin entrar a valorar las preferencias de los editores por la mayúscula inicial, el Amor personificado (normalmente alternando con Deus) se puede leer en las siguientes cantigas del corpus profano (LPGP): 11.12, 14.2, 22.6, 11, 14, 23.1, 25.14, 15, 30.24, 38.1, 45.3, 47.11, 19, 50.3, 56.9, $63.40,65,71,64.25,66.2,75.15,94.14,16,96.3,4,97.17,24,40,106.6,14,111.5,114.5,123.7$, $125.26,133.4,151.15,152.4,15,154.7,157.15,18,62$.

${ }_{18}$ Formas de la función re-creativa o metamítica de la clasificación de Romojaro, Funciones, p. 133 y ss. 
Pero Gomez Barroso (V 592-593, LPGP 127.4)

Do que sabia nulha ren non sei, polo mundo, que vej' assi andar;

e, quand' i cuido, ei log' a cuidar, per boa fé, o que nunca cuidei:

ca vej' agora o que nunca vi

e ouço cousas que nunca oí

Aqueste mundo, par Deus, non é tal

qual eu vi outro, non á gran sazon;

e por aquesto, no meu coraçon,

aquel desej' e este quero mal,

ca vej' agora o que nunca vi

e ouço cousas que nunca oí

[...]

E non daria ren por viver i

en este mundo mais do que vivi.

Hesíodo, en los vv. 106-201 de los Trabajos y días, relata el mito de las razas o de las cinco edades. Según el poeta, en la sucesión de las cinco edades (Oro o de Cronos, Plata, Bronce, Héroes que lucharon en Troya y Tebas, y la de Hierro, en la cual vive su generación) se refleja la decadencia de la humanidad. Al poeta le interesa, sobre todo, describir los horrores de la edad de Hierro, la presente, degenerada moralmente, y que tiende hacia la injusticia total. Paralelamente el autor de la cantiga ${ }^{19}$ ofrece una sátira moral en la que muestra su añoranza por el tiempo pasado. Ahora bien, si en el referente mítico Hesiódico (u ovidiano en Met. I, 70-163), la edad de oro se suele situar en el pasado remoto, en la cantiga ese mundo ideal se sitúa en una época en la que el poeta ha vivido no ha mucho tiempo ( $c f r$. la segunda cobla: «Este mundo, por Dios, no es como el que yo he conocido no hace mucho tiempo; por eso en mi corazón deseo aquel y desprecio este, [estribillo:] pues ahora veo lo que nunca vi y oigo cosas que nunca oí»). Con un desesperanzador remate final tras la cuarta cobla: «Y no daría nada por vivir en este mundo más de lo que ya he vivido en él».

Con todo lo dicho, no quisiera que de esta falta de concurrencias exactas entre el mito clásico grecolatino y la cantiga se pudiera inferir la opinión errónea de que este es el único (tenue y delgado) punto de unión entre ambas literaturas. $\mathrm{El}$ análisis literario permite establecer una serie de influencias o reminiscencias literarias grecolatinas en estos poemillas que, sin poder confirmar que sean de forma directa, nos invitan a reflexionar sobre los insignes antecedentes de la cantiga en la producción literaria del mundo antiguo grecolatino. Y, para demostrar este aserto, me voy a centrar en algunos aspectos concretos de la llamada cantiga de amor ${ }^{20}$. Son

19 Cfr. un comentario algo más extenso en Alvar y Beltrán, Antología, núm. 25.

${ }^{20}$ En la poética fragmentaria contenida en el Cancionero de la Biblioteca Nacional nos viene ya dada una definición de los tres géneros de cantigas que pueden reconocerse en la lírica profana medieval gallego-portuguesa: cantiga de amor, cantiga de amigo y cantiga de escarnio y maldecir. 
estas composiciones que reflejan una versión peculiar del amor cortés, decantado muy intencionadamente hacia la coita de amor, es decir, el penar del trovador por un amor fatal, sin solución, adornado con algunos hiperbólicos halagos a las virtudes de la senhor. Esta continua recurrencia a la muerte por amor y la ausencia casi absoluta del goce erótico, así como otras muchas diferencias de estilo, han llevado al consenso en gran parte de la crítica sobre la inferioridad de este tipo de composición con respecto a la lírica provenzal, pero, curiosamente, la acercan más al poema lírico clásico grecolatino ${ }^{21}$. En efecto, en lo que respecta al contenido, la cantiga de amor gallego-portuguesa ha recogido gran parte de los géneros de composición, la temática, tópica y motivos eróticos que estaban ya perfectamente aquilatados en las composiciones del género amatorio de la antigüedad grecolatina.

Sirva de ejemplo la siguiente cantiga de Airas Nunez:

\section{Airas Nunez (B 882, V465, LPGP 14.8) \\ Nostro señor, ¿̇e porque foi veer ũa dona que eu quero gran ben e querrei sempre ja, mentr' eu viver, e que me faz por si perder o sen? Pero ela faça quanto quiser contra min, ca pero me ben non quer non leixarei de a servir por én}

En esta cantiga de rasgos epigramáticos de apenas siete versos se concentran algunos de los tópicos eróticos más frecuentes de la elegía y la poesía epigramática clásica: el amor a primera vista, la locura de amor, la pérdida del juicio (del sen), la puella (la amante) esquiva, la irrisor amoris (la que desprecia al enamorado o los dioses tutelares del amor) o el servitium amoris (la esclavitud de amor). No son referencias míticas, ciertamente, pero su anclaje en la literatura clásica sí suele estar vinculado por lo general a un contexto mitológico. Por ello las siguientes líneas estarán dedicadas a repasar muy brevemente algunos de estos ecos de tradición clásica, al menos en los más representativos.

El amor a primera vista. Una de las vías para el enamoramiento con más peso literario y filosófico es la mirada. Los ojos hacen de conducto físico por el cual penetra el amor hasta lo más profundo del alma. Este tópico, de indiscutible rai-

La crítica moderna, no obstante, atendiendo a otras cuestiones de forma y contenido y, sobre todo, a la variada casuística que presentan, ha intentado con buen criterio reformular esta distinción para tratar de englobar otras divisiones y géneros «menores» o «híbridos» hasta ahora no contemplados. Sobre los problemas de catalogación a causa de esta inversión e hibridación temática o por el cruce de géneros hay abundante bibliografía. Un nuevo ensayo de clasificación de la cantiga se puede leer en BREA, $L P G P$, pp. 25-26.

${ }^{21}$ Cfr. Pena, Literatura galega, p. 152: «Nuestra cantiga representa la evidencia de un amor platónico, puro, ya que está dedicada siempre a una doncella. Es por eso que en la cantiga de amor existe una enunciación sintética del amor frente a la explosión de sensualidad provenzal». Para las características de la cantiga de amor, cfr. ibidem, 152-153. 
gambre clásica, cobrará una importancia crucial, ya que pasa a ser motivo literario de primer orden de las doctrinas neoplatónicas y, por consiguiente, en la literatura y la filosofía bizantinas, fuente directa del petrarquismo y, ya antes, de la poética medieval (y renacentista) erótica. Ligado al anterior, la teoría filosófica de la emanación de hermosura a través de los ojos, o el amor como deseo inyectado en el alma por un flujo de belleza que procede del ser querido y se recibe por los ojos, ya está esbozada en Platón (Fedro 251b y ss.), pero se le pueden rastrear orígenes más antiguos $^{22}$. Y derivado de este motivo estaría el tópico helenístico de «los dardos de la mirada" (ciertamente no es helenístico, porque ya antes se puede leer en el Agamenón 742, pero será ampliamente utilizado en época helenística), como variante más antigua del mitema de las flechas de Eros. Y también derivados de este estarían el tópico de que se puede gozar con la sola visión del amado o los poderes de arrastre que tiene sobre el amante la mirada de la amada.

Este motivo está ampliamente representado en la cantiga de amor gallegoportuguesa, por lo que no es extrańo encontrar comienzos como el que sigue, del que además se podría decir que constituye una hermosa teichoscopía invertida:

Pedr'Eanes Solaz (A 283, B 1220, V 825, LPGP 117.1)

A que vi ontr'as amenas,

¡Deus!, como parece ben!

e mirey-la das arenas:

des i penado me ten!

Eu das arenas la mirey,

e des enton sempre peney!

En el siguiente ejemplo el trovador, al verse separado de su dama, perdió el placer de verla, por lo que considera haber quedado ciego en ese mismo momento:

Joâo Garcia de Guilhade (A 231, B 421, V 33, LPGP 70.49)

U m'eu partí d'u m'eu partí,

logu'eu partí aquestes meus

olhos de veer, e, par Deus,

quanto ben avia perdí;

$\ldots$

Ca ja ceguey, quando ceguey;

de pran ceguey eu logu'enton,

e ja Deus nunca me perdon,

se ben vejo, nen se ben ey;

22 Los textos más representativos de este tópico en la literatura clásica son sin duda los de la tragedia. En efecto, la emanación de hermosura se recoge en el Agamenón (v. 742) y las Suplicantes de Esquilo (v. 1004); en la Antígona (v. 795) y los fragmentos sofócleos (161, 430, 733), y en el Hipólito de Eurípides (v. 525). 
Y, enlazando con el motivo de la locura de amor que se estudiará a continuación, podemos cotejar los siguientes ejemplos en los que el amor a primera vista provoca la enajenación o locura del amante:

Don Denis (B 503, V 86, LPGP 25.33)

Como me Deus aguisou que vivesse em gram coita, senhor, desque vos vi!

Joâo Garcia de Guilhade (A 229, B 419, V 30, LPGP 70.9)

[...]

Pero non devia a perder ome que ja o sen non á de con sandece ren dizer e con sandece digu'eu ja: os olhos verdes que eu vi me fazen ora andar assi

No he podido resistirme, para terminar con el motivo de los ojos, traerles dos fiindas, una de una cantiga también de Joâo Garcia de Gilhade y la segunda de Johan Soarez Coelho:

Joâo Garcia de Guilhade (A 237, LPGP 70.22)

[...]

d'este meus olhos a coyta que an:

choran e cegan, quand'alguen non veen, e ora cegan por alguen que veen.

Johan Soarez Coelho (A 237, LPGP 79.48)

$[\ldots]$

dề-lo dia 'n que vus non vi,

mia senhor, nunca despois vi

para que pueda cotejarse con una de las más breves epístolas eróticas de Filóstrato, una de las epístolas, que, al igual que para muchas cantigas, se podría defender su carácter epigramático y que tan bien recoge el mismo giro literario de la paradoja:

Filóstrato, Epistola 52

Amar no es una enfermedad, sino no amar.

Pues si amar nace de ver, ciegos están los que no $\operatorname{aman}^{23}$.

${ }^{23}$ Una curiosa reformulación de este mismo topos sería la del «amor de oídas», frente al convencimiento de que el amor se experimenta a través de la vista, el tópico del «amor de oídas» está muy bien documentado en la literatura erótica epistolar (Aristéneto, Ep. 1.26 y Teofilacto Simocatas, Ep. 36) y en otros pasajes de contenido erótico: $c f r$. Ateneo, Banquete de los eruditos $13.575 \mathrm{~A} \mathrm{o}$ la novela de Aquiles Tacio 2.13. 
El furor amoris o erōtikè manía. El amante herido comienza su locura. El sentimiento de los amantes rebasa la frontera de la ecuanimidad y el equilibrio, y

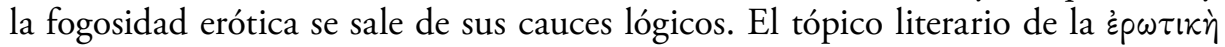
$\mu \alpha v i \alpha$ ya nos viene formulado en el Fedro platónico (265b) y los testimonios en la literatura clásica son frecuentes. Un género que se muestra especialmente accesible a este tipo de páthos es la tragedia. Sirvan de ejemplo dos pasajes paradigmáticos de la obra de Eurípides: el parlamento de la nodriza en los vv. 100 y ss. de Medea, o las estremecedoras palabras de Fedra en Hipólito (vv. 240 y ss.):

¡Desdichada de mí! ¿Qué es lo que he hecho?

¿Por qué recodo de la recia sensatez me desvié?

Estoy loca, me hizo caer la sinrazón de un dios.

En relación directa con el amor como manía o incluso tarachế (recuérdese que la turbación que produce el sentimiento amoroso ha sido atacada por determinadas doctrinas filosóficas, como el epicureísmo, que postulaba que el amor comportaba un cúmulo de inconvenientes reńidos con la ataraxía del sabio) puede ponerse una de las definiciones que se leen para el amor en el Erótico de Plutarco (Amat. 16 y 18 = Moralia 758E, 763A): el amor como una forma de $\mu \alpha v i \alpha$ o agitación del alma enviada por un dios, el amor como el sálos psychês (una marejada del alma u oleaje anímico).

Será también una constante en la cantiga de amor la pérdida del «buen sentido» del amante ante el rechazo de la amada esquiva:

Joâo Garcia de Gilhade (A 229, B 419, V 30, LPGP 70.9)

Amigos, non poss'eu negar

a gran coyta que d'amor ei

ca me vejo sandeu andar,

e con sandece o direy:

os olhos verdes que eu vi

me fazen ora andar assi.

[...]

Pero non devia perder

ome que já o sen non á

e con sandeu ren dizer

e con sandeu digu’eu já

Locura y muerte es lo único que puede esperar el amante. Y así se expresa en la fiinda de esta cantiga:

Joâo Garcia de Gilhade (A 232, B 422, V 34, LPGP 70.1)

Sandec'e morte, que busquey sempr'i,

e seu amor mi deu quant, eu buscava!

En el siguiente ejemplo (extraído de una cantiga de amigo), la joven reprocha a la madre que, por haber impedido el encuentro de los enamorados, aquel ha caído en un estado de enajenación que solo la intervención divina ha impedido su muerte: 
Estevan Fernandiz d'Elbas (B 1091, V 682, LPGP 33.6)

$\mathrm{O}$ meu amigo, que por mim o sen perdeu, ay madre, tornad'é sandeu, e poys Deus quis que ynda non morreu e a vós pesa de lh'eu querer bem,

Ahora bien, un mismo motivo puede dar lugar a una cantiga de escarnio. En efecto, se trata de la reutilización de un determinado tópico o motivo literario erótico para explotarlo en un contexto de carácter burlesco en un claro ejemplo de hibridación o nivelación genérica. En el pasaje que se cita a continuación la sátira se hace contra el amante que muere de amor. Nótese, además de la conversión del motivo en el contexto del escarnio literario, la velada irreverencia (Roi Queimado había muerto de amor en sus cantigas por una dama a la que amaba mucho; y para dárselas de mejor trovador, se dejó morir en sus cantigas; pero resucitó después, al tercer día).

Pero Garcia Burgalês (B 1380, V 988, LPGP 125.45)

Roy Queymado morreu con amor en seus cantares, par Santa Maria, por hunha dona que gran ben queria;

e, por se meter por mays trobador, por que lh'ela non quiso ben fazer, feze-s'el en seus cantares morrer; mays resurgiu depoys, ao tercer dia.

Esto fez el por hunha su senhor...

Amor y muerte pueden llevar al experimento poético de la paradoja. Este ejemplo, tomado de una fiinda de Pero d'Armea, es evocador del vivo sin vivir en mi teresiano:

Pero d'Armea (B 1086, V 678, LPGP 121.18, vv. 17-20)

[...]

que vos non pês o que vos rogarey

de depoys, se vos prouguer, morrerey,

e sse vos prouguer, o que vos direy

e pois morrer, ja mays non morrerei.

Por último, ilustrativa de la locura de amor y de otras formas poéticas que tienen su correlato en la literatura clásica, es sin duda la siguiente cantiga de Joâo Baveca, una tensón de tono idílico sobre quién está más loco, el villano enamorado de la dama noble, o el noble enamorado de la villana, de quienes jamás obtendrán los favores:

Joâo Baveca (B 1221, V 82, LPGP 64.22)

-Pedr'amigo, quer'ora hûa ren saber de vós, se o saber poder. 
Do rafeç'ome que vai ben querer mui boa dona, de que nunca ben atende já, e o bôo que quer outrossi ben muy rafece molher, pero que lh'esta queira fazer bem: qual d'estes ambos he de peior sém?

Dentro también de esta misma esfera de la enajenación erótica estaría la ceguera del enamorado, o la perturbación psicofísica que impide al amante ver los defectos físicos del ser querido y que tiene su origen más preclaro en el célebre pasaje de la República de Platón (474d-e). El caecus amator, que será uno de los más rentables motivos en la elegía erótica latina, tiene alguno de sus mejores ejemplos en la epigramática griega; cfr. AP 12.5, 193, 198, 244 y 256 (Estratón de Sardes). En la cantiga será la belleza sin par de la senhor la que recoja este motivo o la sýnkrisis de la dama con el resto de las mujeres, comparación en la que siempre resulta vencedora.

Los signa amoris. Del catálogo de sintomas de amor que ya vinieran enunciados desde los poemas sáficos (el más célebre, sin duda, el fr. 31 V., imitado por Catulo 51), la cantiga recoge buena parte de sus elementos constitutivos. La duda y el dilema retórico de los amantes, el asaltarse con continuas y hostigadoras preguntas, y solo a veces proporcionarse a sí mismos la respuesta, es un recurso estilístico de fecunda utilización. Quedaría englobado en el tropo de la subiectio o hypophora ${ }^{24}$. Ahora bien, entre los reflejos físicos externos de estos síntomas hay tres que destacan por su especial frecuencia: el llanto (el correr incontenible de lágrimas por las mejillas es una imagen obligada en todos los pasajes de este tipo), el insomnio (el amante enamorado no puede conciliar el sueño) y la mudez: el amante, como a la lesbia Safo que se le quebraba la lengua, queda paralizado en presencia de la dama amada, pierde la facultad de hablar y no puede expresar su amor ${ }^{25}$. Sirvan de ejemplo los siguientes textos:

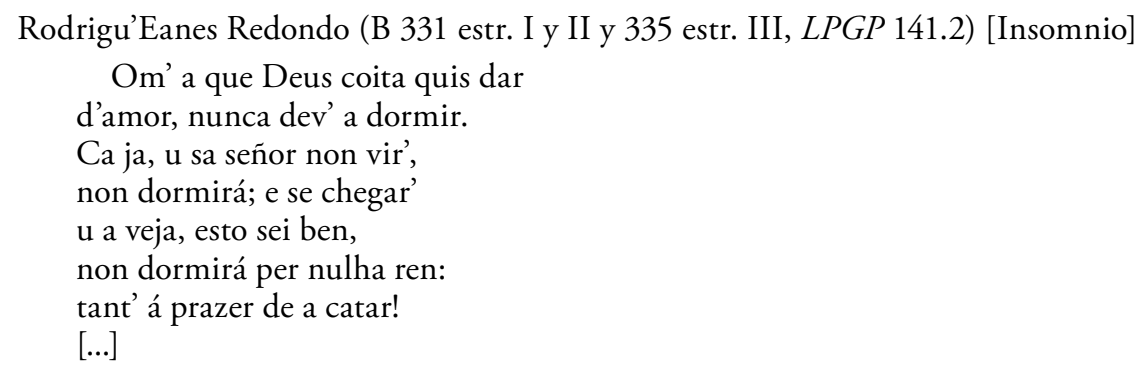

${ }^{24}$ H. Lausberg, Manual de retórica literaria, Madrid, Gredos, 1966, $\$ \$ 771-775$.

${ }^{25}$ No confundir la mudez con el amor inconfesable, motivo del que hay muchísimos ejemplos en el corpus de cantigas: Pero d'Armea, «Muytos me vêen preguntar» (B 1085, V 677, LPGP 121.13), Martin Soarez, «Muitus me vêem preguntar» (B 160, A 48, LPGP 97.19). Relacionado con

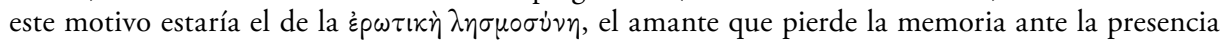
de la amada: Pero Garcia Burgalês, «ant'ela, todo lh'escaesçerá» (B 189ª A 85, LPGP 125.38) o el ¡Pues ella consigue que lo olvide todo! («cá mh’o faz ela tod'escaecer!» de B192, A 88, LPGP 125.48). 
ca des que mia senhor non vi, nunca dormi;

[...]

ja o dormir, mentr'eu durar', perdudo [ei], pois est assi,

que, u a non vi, non dormi;

[...]

¿i quen dormirá
con tan gran prazer ou pesar?

Para el insomnio, véase también Bernal de Bonaval (B 1069, V 660, LPGP 22.1) y Fernand d'Esquio (B 1294, LPGP 38.1)

Roi Paez de Ribel (A 191, B 342, LPGP 147.19) [Mudez]

Un dia que vi mia senhor, quis-lhe dizer lo mui gran ben que lh'eu quer', e como me ten forçad' e pres' o seu amor, e vi-a tan ben parecer que lhe non pude ren dizer!

Como ya se ha señalado, un mismo motivo erótico puede constituir un género híbrido si se reutiliza el contenido en una cantiga de otro tipo. Uno de los motivos asociados a los signa amoris y habitual en contextos eróticos es el símil del amante azorado como «buey picado por un tábano» (cfr. Longo 1.3.6; 2.7.4 o Apolonio de Rodas 1.1265; Aristéneto, Ep. 2.18.7). Esta imagen, cuya fuente directa estaría en el pasaje 251d del Fedro platónico, está recogida también en una cantiga, pero no de contenido erótico, sino de escarnio, contra un cobarde:

Alfonso Mendez de Besteiros (B 1558, LPGP 7.4)

Don Foâo, que eu sei á preço de livâo, vedes que fez ena guerra -daquesto soo certâo:

sol que viu os genetes, como boi que fer tavâo,

sacudiu-se e revolveu-se, al-

çou rab' e foi sa via a Portugal ${ }^{26}$.

El juramento de amor o aphrodisios hórkos. Las relaciones familiares, de amistad o camaradería, las de hospitalidad o philoxenía, etc., se fundamentan sobre una serie de «leyes» morales no escritas de gran estima en el mundo clásico. Se requiere en estas relaciones entrega absoluta y garantía de fidelidad al pacto por encima de cualquier otra circunstancia. Pues bien, si esta actitud social se trasvasa, con la correspondiente reelaboración literaria, al ámbito del amor, el compromiso sagrado que en la Antigüedad significa el juramento para las relaciones sociales se aplica con

${ }^{26}$ Confróntese con la epístola erótica de Aristéneto II 18.7: «Después de recibir la emanación de hermosura a través de los ojos, se prendió de fuego erótico, y como un buey atormentado por un tábano, perdió todo sosiego». 
los mismos cargos y obligaciones éticos para las eróticas. Las obligaciones, el compromiso entre amigos que comporta el foedus amicitiae, el juramento de amistad, se transforman en el juramento de amor; esto es, todas aquellas obligaciones que el juramento de fidelidad al amigo llevan implícitas pasan ahora al mundo de la pareja. Ahora bien, desde el punto de vista literario el motivo ha sufrido una proverbial reformulación. En efecto, en contra de todo lo dicho anteriormente: transgredir o conculcar el juramento de amor está considerado como algo ḋ $\pi \circ i v \mu o \varsigma$ (sin castigo), hasta el punto de que los dioses no lo tienen en cuenta (Hesíodo, fr. 187). Así lo expresa ya Platón en el Banquete (Symp. 183b): «Y lo que más nos choca, como precisamente dice el vulgo, es que incluso si hace un juramento, él (sc. el enamorado) es el único que, si transgrede el pacto, alcanza el perdón de los dioses, pues afirman que el juramento de amor no es válido».

En el siguiente ejemplo se produce una nueva inversión del topos: el juramento fingido. El trovador lamenta y denuncia en la cantiga que son los juramentos y quejas de los amantes fingidos los que perjudican a los que de verdad aman, ya que por culpa de aquellos han perdido la credibilidad:

Joâo Baveca (B 1108, V 699, LPGP 64.20)

Os que non aman nen saben d'amor fazen perder aos que amor am.

Vedes porque: quand'ant'as donas vam, juram que morren por elas d'amor,

e elas saben poys que non é 'ssy;

e por esto perç'eu e os que ben

lealmente aman, segundo meu sén.

Tampoco desde el punto de vista del personaje femenino va a faltar en la cantiga la figura del amante perjuro. Los ejemplos más granados de la literatura antigua serán Jasón para con Medea en el drama homónimo de Eurípides y Teseo para con Ariadna en el poema 64 de Catulo:

Eurípides, Medea 492 ss.

He perdido la confianza en los juramentos, y no puedo saber

si crees que los dioses de antaño ya no gobiernan

o que ahora hay leyes nuevas para los hombres.

porque sabes bien que has sido perjuro conmigo.

Catull. 64.132-135

¿Así, pérfido, a mí alejada de los altares patrios,

pérfido Teseo, me has abandonado en una playa desierta?

¿Así te marchas olvidando el numen de los dioses y,

¡ay, sin memoria!, llevas a tu patria sacrílegos perjurios? ${ }^{27}$

27 Traducción de A. Ramírez de Verger, Catulo. Poesias, Madrid, Alianza, 1988. 
Igualmente en la cantiga la joven se queja de que el amigo no llegó al término del plazo convenido y lamenta el engaño del amado perjuro:

Don Denis (B 566, V 169, LPGP 25.50)

Nom chegou, madr', o meu amigo, e oj'est o prazo saido,

Ai madre, moiro d'amor!

$[\ldots]$

E oj'est o prazo passado, porque mentio o perjurado.

Ai madre, moiro d'amor!

Fernan Froiaz (B 804, V 388, LPGP 42.2)

Juravades mi vós, amigo, que mi queriades mui gran ben, mais eu non o creo per ren, por que morastes, o digo, mui longi de min e mui sen meu grado Muitas vezes mi jurastes e sei ca vos perjurades, mais, poilo tanto jurades, dizede por que morastes mui longi de min e mui sen meu grado Muito per podedes jurar, que ja, en quanto vivades, que nunca de min ajades amor, por que fostes morar mui longi de min e mui sen meu grado [...]

Johan Perez d'Aboim (B 666, V 269, LPGP 75.22)

[...]

Vistes, u jurou que non ouvesse nunca de min ben, se no veesse? oje dia cuidades que venha? Viste' las juras que jurou enton, que verria sen mort' ou sen prison? oje dia cuidades que venha? Viste' las juras que jurou ali, que verria, e jurou-as per mi: oje dia cuidades que venha?

Y en el último, también de Don Denis, el motivo del perjurio de amor se complementa con otro de los grandes tópicos amatorios de la Antigüedad clásica: el amante que le habla a las flores y los árboles: 
Don Denis (B 568, V 171, LPGP 25.2)

Ai flores, ai flores do verde pino,

[...]

Se sabedes novas do meu amado,

aquel que mentiu do que mh'a jurado,

Ai Deus, e u é?

El servitium amoris o érōtos douleía. Se trata de uno de los tópicos de mayor riqueza en la literatura clásica de tema erótico y de mayor fortuna en la cantiga gallego-portuguesa. A propósito del tópico del juramento de amor, se ha argumentado que su origen estaba en una contaminatio de conceptos, y que una realidad social, como es el pacto de fidelidad (sacramentum fidei), el de hospedaje (la xenía) $\mathrm{y}$, en definitiva, el de amistad en todas sus vertientes (foedus amicitiae), mediante la pertinente redefinición literaria, pasaba a ser el pacto de amor entre dos enamorados. Pues bien, en este apartado estaríamos ante un caso semejante: la esclavitud en el Mundo Antiguo es una realidad social, una relación de vasallaje entre el esclavo y el amo, en la que, es bien sabido, el esclavo carece de entidad jurídica, por lo que está sometido a una absoluta subordinación a su señor y debe estar presto a las peticiones, del tipo que fueren, que provengan de aquel. Por lo tanto, si mediante la correspondiente reelaboración literaria se trasvasan algunos conceptos de esta realidad, y a la amada pasamos a considerarla el amo y al amante el esclavo, están asentadas las bases que constituyen el consabido tópico del servitium amoris, tópico ya enunciado desde Platón por boca de Pausanias en el Banquete (Smp. 183a): «Hacer las mismas cosas que los amantes con sus amados... pronuncian juramentos, duermen en sus puertas y voluntariamente soportan una esclavitud que ni siquiera soportaría un esclavo». Este tópico irá transmitiéndose a lo largo de la Antigüedad tardía y el Medievo para llegar a la literatura provenzal casi exactamente en los mismos términos: el régimen jurídico feudal fijaba los derechos del vasallo y los deberes del señor. El trovador adopta el papel de vasallo de la sua senhor, así como las obligaciones que esta sumisión comporta ${ }^{28}$ :

\author{
Vasco Gil de Soverosa (A 154, LPGP 152.1) \\ Ay mia senhor! quero-vus preguntar \\ pois que vus ides e eu non poss' ir \\ vosco per ren, e sen grad' a partir- \\ m'-ei eu de vos e de vosco morar, \\ Ay eu cativo! por Deus ¿que farei? \\ Ay eu cativo, que non poderei \\ prender conselho, pois sen vos ficar'!
}

${ }^{28}$ Nótese que en la MedDB: Base de datos Lírica Profana Galego-Portuguesa se pueden leer 163 concurrencias del verbo servir y 12 de servidor (seu, sou, vosso, etc.). Sobre la relación entre 'servir' y 'amar' (y 'trovar') es imprescindible la consulta de A. Pichel, Ficción poética e vocabulario feudal na lírica trovadoresca galego-portuguesa, A Coruña, Diputación, 1987. 
Frente a esta sumisión incondicional, en el siguiente ejemplo el autor se queja de que el amor de su dueña terminará por matarlo, por lo que la senhor debería buscarse mejor consejero que le recuerde sus obligaciones con sus vasallos:

Martin Soarez (A 59, B 170, LPGP 97.34)

Por Deus, senhor, non me desenparedes

a voss'amor que m'assy que matar;

$[\ldots]$

e non tenh'eu que é torto nen mal

d'amar home sa senhor natural,

ant'é dereito e vos vol'entendedes.

Somos conscientes de que han quedado sin ejemplificar algunos de los motivos o tópicos más representativos como la erotodídaxis (el magisterium amoris), la militia amoris, el rival en amores (el anterastếs griego o los miscradores de las can$\operatorname{tigas}^{29}$ ), la renuntiatio amoris (amantes que, no pudiendo soportar por más tiempo el desdén de la amada, deciden, a su pesar, poner fin a la relación), el kômos (con la galería de motivos que lo componen como la thyraulia, el paraklausithyron, el exclusus amator...), los adýnata o impossibilia, el topos del amor agridulce (glykýpikros), la queja o schetliasmós, el propemptikón o despedida ${ }^{30}$, etc., algunos de ellos más propios quizá de la cantiga de amigo: composiciones en las que se pone en labios de una mujer un lamento, una invocación, una llamada o una queja amorosa dirigida al amigo, a la madre o a las amigas. Pues bien, la relación de este tipo de composición con sus antecedentes en la literatura griega ha sido bien estudiada ${ }^{31}$. En efecto, los gynakeîa mélé de la literatura griega antigua han sido cada vez mejor documentados y clasificados y sus lugares comunes podrían haber llegado, por distintos procedimientos, hasta la lírica medieval. En este tipo de cantos de mujer vamos a encontrar los mismos ciclos temáticos de las bailadas, barcarolas o mariñas o de romería, al mismo tiempo que este universo femenino permite distinguir las de alborada, la malmaridada, la malmonxada o la de tejer, entre otros.

Solo podemos concluir insistiendo en la cuestión de si estos puntos concurrentes entre la cantiga medieval gallego-portuguesa y la literatura antigua grecolatina no son más que realidades literarias de carácter formal y de contenido inherentes al acervo folclórico, culto y popular, que se van a producir siempre que se den condiciones culturales y socioeconómicas análogas; o si, en cambio, habría que tener pre-

${ }^{29}$ Los lausengiers de la lírica provenzal. La cantiga «Mentre non soube per min mia sennor» de Pero Garcia Burgalês (A 110, B 219, LPGP 125.22) constituye un ejemplo de este raro motivo en la cantiga gallego-portuguesa adornado además con una curiosa variante del paraklausithyron: el amante, el exclusus amator, apostado a la puerta de la dama pero sin querer acercarse a ella.

${ }^{30}$ Cantiga de amor (motivo do comjat), según la clasificación del $L P G P$, p. 27. Ejemplos de este tipo pueden leerse en Pai Gomez Charinho (B 813, V 397, LPGP 114.13) o en Joâo Airas de Santiago (B 954-955, V 542, LPGP 63.64).

31 Información exhaustiva en Gangutia, Cantos de mujeres y «Los «cantos de mujeres». Nuevas perspectivas», art. cit., n. 13. 
sentes los orígenes atávicos, arraigados en la literatura grecolatina y considerar que los dos grandes tamices por los que estos han sido cribados, la canción provenzal y la moaxaca y la jarcha mozárabe, no son sino dos estadios fundamentales y paralelos de un hermoso y extraordinario continuum cultural y literario.

RECIBIDO: 02-12-2019; ACEPTADO: 01-06-2020 